\title{
Morphology and mechanical characteristics of some TBCs used for internal combustion valves
}

\author{
Marius PANȚURU ${ }^{1 \mathrm{a},}$ Daniela CHICET ${ }^{2 \mathrm{~b}^{*}}$, Ovidiu MOCĂNIȚA ${ }^{1 \mathrm{c}}$, Marcelin \\ BENCHEA ${ }^{1 \mathrm{~d}}$ and Corneliu MUNTEANU ${ }^{1 \mathrm{e}}$ \\ ${ }^{1}$ Technical University "Gheorghe Asachi" of Iasi, Mechanical Engineering Department, 6 D. \\ Mangeron Blvd, Iasi, Romania \\ ${ }^{2}$ Technical University "Gheorghe Asachi" of Iasi, Materials Science and Engineering Department, \\ 41 D.Mangeron Blvd, Iasi, Romania

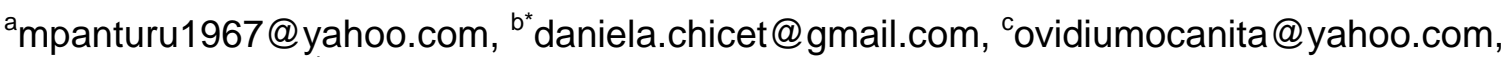 \\ dmarcelin_ben@yahoo.com, ${ }^{\mathrm{e}}$ cornelmun@gmail.com
}

\section{Keywords: TBC, Internal combustion valves, Morphology, Mechanical characteristics}

\begin{abstract}
Three types of commercial powders have been deposited on the inlet and outlet valve plates in order to increase their lifetime, but especially the temperature in the combustion chamber. The layers were coated by atmospheric plasma spray method. The coatings morphology was analysed using two complementary methods: scanning electron microscopy and X-ray diffraction. The mechanical characteristics analysed were: microhardness, modulus of elasticity and adhesion / cohesion of coatings using scratch tests. Following those tests it was observed that the coatings are physically suited for further tests as thermal barrier coatings (TBC) on the valve discs of internal combustion engines.
\end{abstract}

\section{Introduction}

The distribution system (especially the intake/evacuation areas) of the internal combustion engine is subjected, during its operation, to a series of very complex loads involving: mechanical impact and high frequency micro-slipping, high temperatures with a very large variation, presence of microparticles, etc. Another very important stress factor is the working pressure, which often in combination with other stresses causes damage to the valve disc and implicitly change the contact geometry of the seat of the valve. Taking into account all this, but also that the new regulations related to the emission of combustion gases will become more and more strict, we come up with the proposal to cover the valves discs with layers as thermal barrier.

Thermal barrier coatings have initially been used for gas turbine elements protection applications, in the specialized literature being available multiple studies on this type of use. [1-5] Starting from these studies, the range of applications has been expanded so that over the past 20 years, TBCs have found many other applications, one of which is covering the components of diesel engines in order to improve their thermal efficiency, to reduce weight by removing the cooling system, to increase the efficiency by lowering the amount of energy lost through thermal effect and to improve the durability of components [6,7].

Depending on the working conditions, different mechanisms of wear and destruction of TBCs become dominant. These coatings are in fact complex systems formed of the top layer of TBC, the intermediate layer with bonding function that supports the upper layer and the substrate, so that the properties of the whole system influence its lifetime in operation. By analysing the components, it is observed that in the case of the TBC top layer these properties are the microstructure, density, thickness, distribution of the micro-cracks and cohesion in the layer 
(between splats that form it). In the case of the bonding layer, it is the oxidation resistance, the density of the layer, its thickness and the surface roughness [8]. An equally important role for lifetime in operation is the difference in thermal expansion, the residual stresses of the system, but also its geometry. $[9,10]$

The most commonly element used and studied for this type of application is zirconia, because it exhibits a high coefficient of thermal expansion and low thermal conductivity, the last one due to the presence of micropores according to the studies of Zhou et al. [11] The most successful material used is currently yttrium-stabilized zirconia (YSZ) [12].

Thus, in the present study, three types of TBCs were deposited on the discs of the intake and exhaust valve are analysed by the atmospheric plasma jet deposition method (APS) and studied in order to observe their properties: the morphology - analysed by two complementary methods: scanning electron microscopy and X-ray diffraction, and the mechanical characteristics microhardness, modulus of elasticity and adhesion / cohesion of coatings.

\section{Materials and methods}

The three types of coating systems with TBC role proposed for study were deposited on the discs of the intake and exhaust valves by the atmospheric plasma jet deposition method (APS) using the following materials (all of them are commercial powders, manufactured by Metco Oerlikon):

- the bonding layer, common for all samples was produced from $\mathrm{Al}_{2} \mathrm{O}_{3}-\mathrm{NiAl}$ powder;

- the top coat for sample 1 (S1), was produced from $\mathrm{Cr}_{2} \mathrm{C}_{3}-\mathrm{NiCr}$ powder;

- the top coat for sample 2 (S2), was produced from MgZrO - NiCr powder;

- the top coat for sample 3 (S3), was produced from $\mathrm{ZrO}$ - CaO powder.

There were used as substrate discs of intake or exhaust valves, organized as 3 sets of four intake valves and four exhaust valves. The coatings were produced using the facility SPRAYWIZARD 9MCE for atmospheric plasma spraying.

The coating morphology was analysed using two complementary methods: scanning electron microscopy with the Quanta 200 3D microscope (FEI, The Netherlands, 2009) using the Low Field Detector at 1000x/5000x magnification or Z contrast and X-ray diffraction with the XPERT PRO MD (Panalitycal, Netherlands, 2009) diffractometer.

The mechanical characteristics analysed were: microhardness, modulus of elasticity (by indentation) and adhesion / cohesion of coatings using scratch tests, all tests being carried out with the UMTR 2M-CTR Microtribometer, using an indenter with diamond tip Rockwell type, and a force of $20 \mathrm{~N}$ (for indentation), respectively $10 \mathrm{~N}$ for scratch (Progressive Load Scratch Test mode).

\section{Results}

As mentioned before, the microstructure of the top coat is one of the elements that influence the lifetime and the functionality of the coating system. The secondary electron images of the samples surfaces realised at different magnification are presented in Fig. 1, 2 and 3.

In the case of all three samples, the specific structure of the coatings made by thermal deposition formed by splashes (resulted from the partial or total melting of the powders used), micro-cracks and pores of different sizes is observed. 


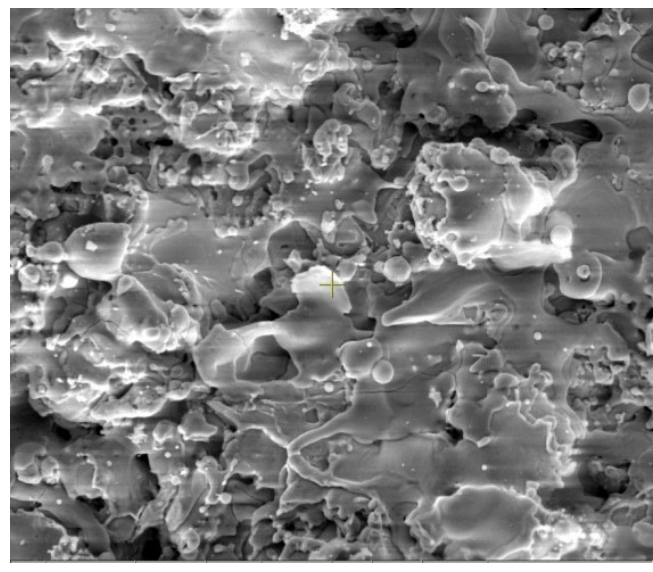

a)

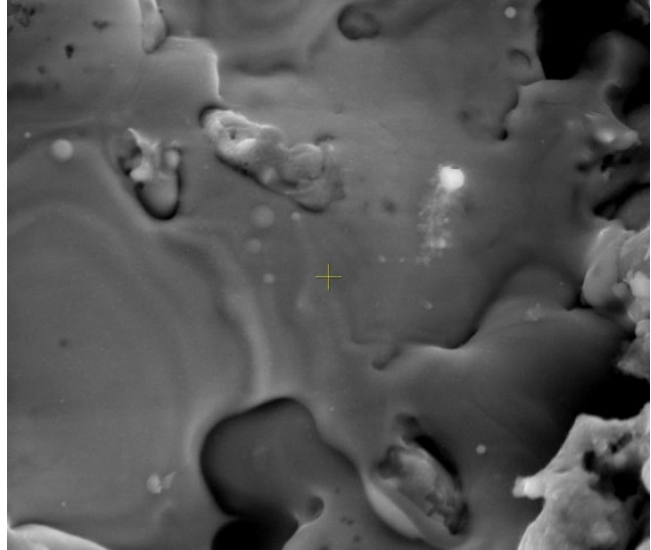

b)

Fig. 1. Typical SEM images of $\mathrm{S} 1\left(\mathrm{Cr}_{2} \mathrm{C}_{3}-\mathrm{NiCr}\right)$ coatings surface morphology:a)1000x; b)5000x.

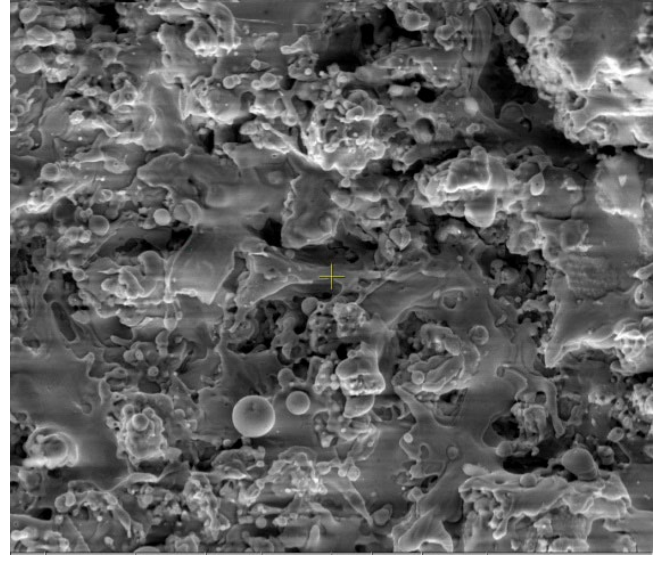

a)

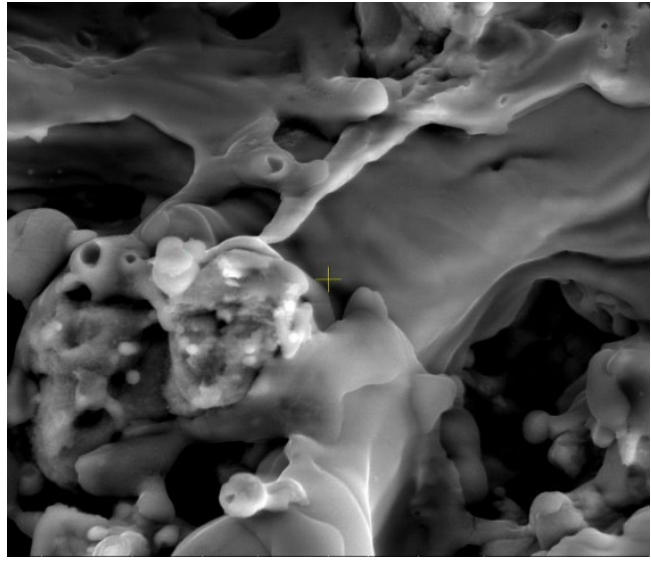

b)

Fig. 2. Typical SEM images of S2 (MgZrO-NiCr) coatings surface morphology: a)1000x; b)5000x.

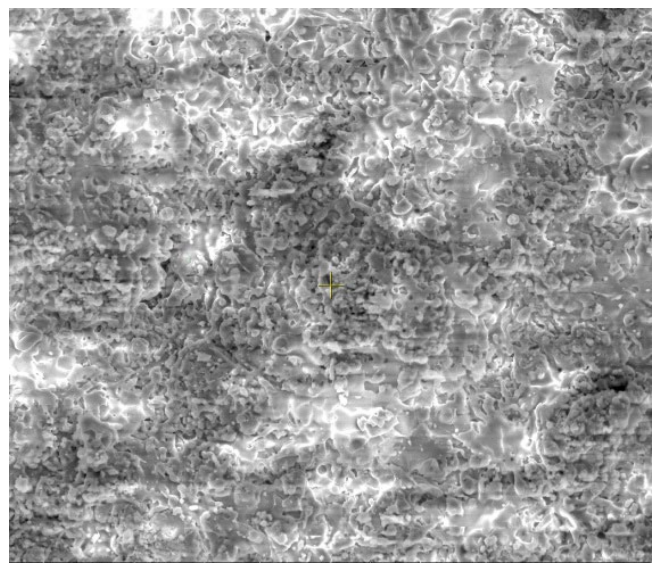

a)

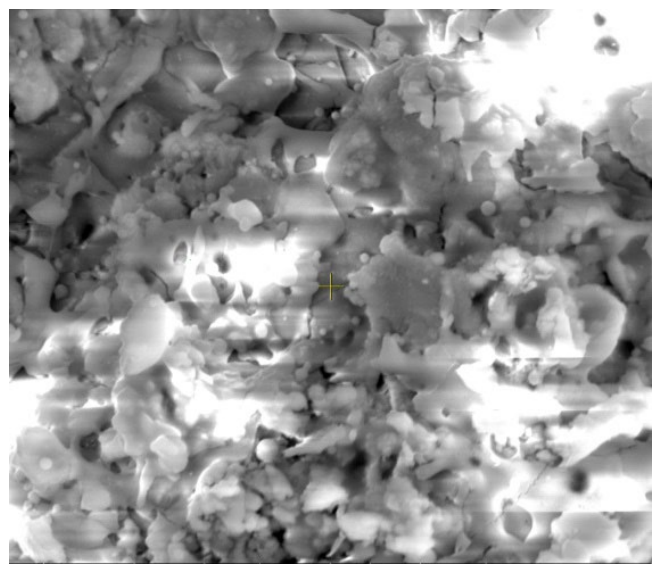

b)

Fig. 3. Typical SEM images of S3 (ZrO - CaO) coatings surface morphology: a)1000x; b)5000x.

Fig. 4 presents the XRD patterns resulted for the three types of thermal barrier coatings studied in the present article. 


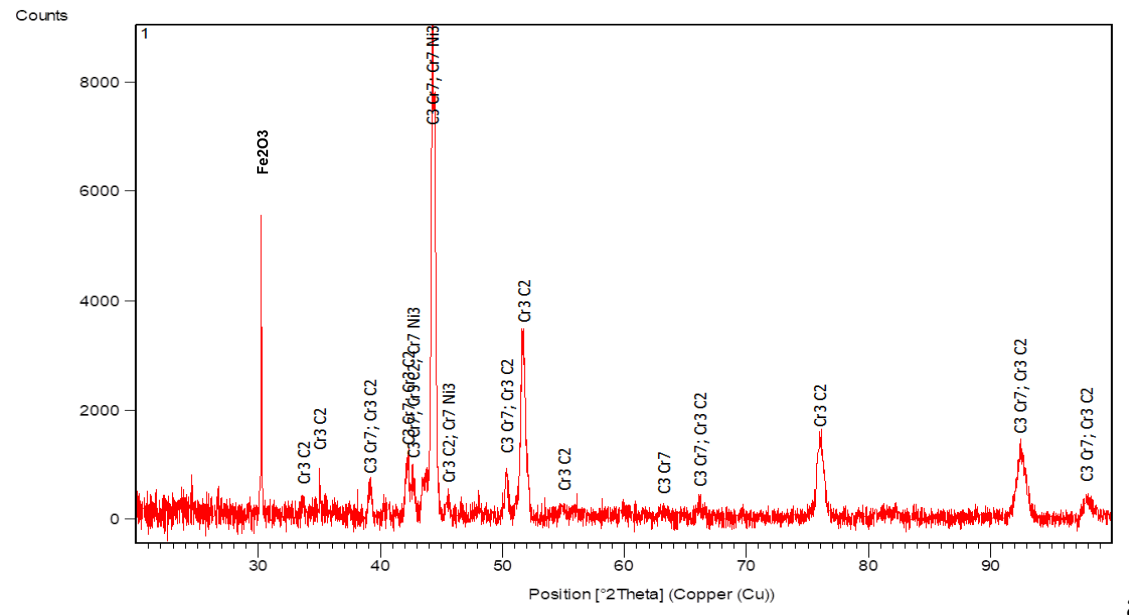

a)

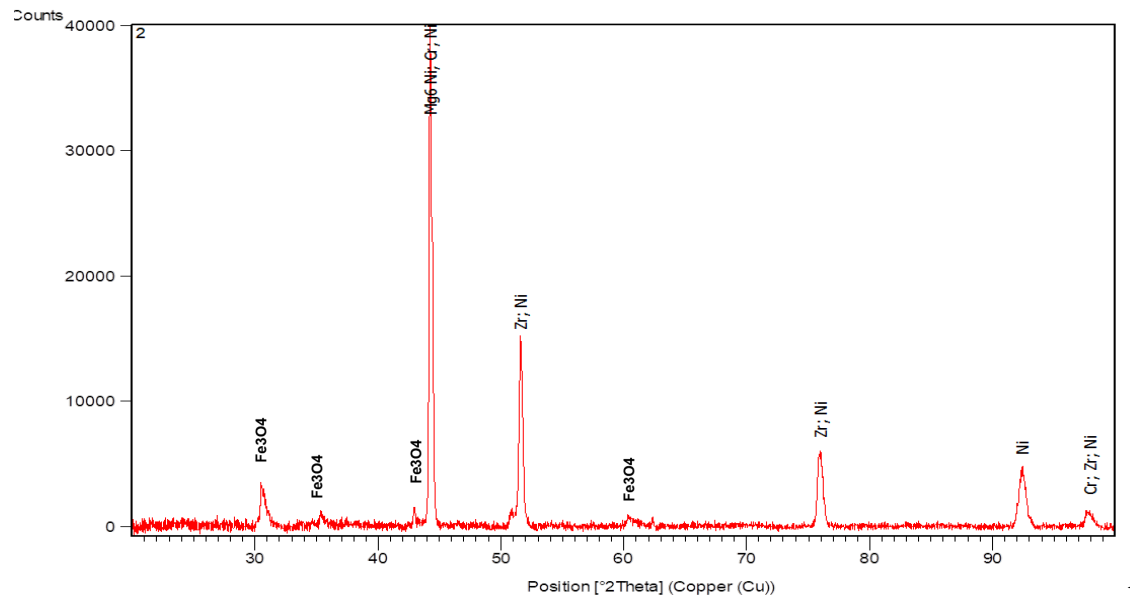

b)

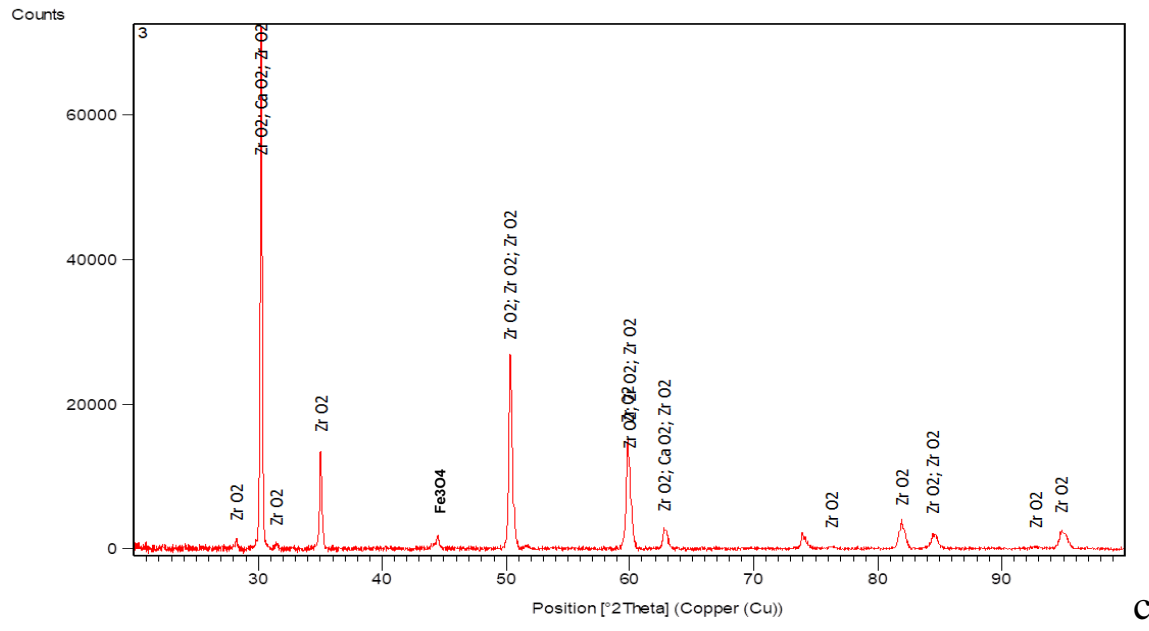

c)

Fig. 4. XRD patterns: a) $\mathrm{S} 1\left(\mathrm{Cr}_{2} \mathrm{C}_{3}-\mathrm{NiCr}\right)$; b) $\mathrm{S} 2(\mathrm{MgZrO}-\mathrm{NiCr})$; c) $\mathrm{S} 3(\mathrm{ZrO}-\mathrm{CaO})$.

The following phases are observed on the XRD patterns:

- for the $\mathrm{Cr}_{2} \mathrm{C}_{3}-\mathrm{NiCr}$ coating: chromium carbides (orthorhombic $\mathrm{Cr}_{3} \mathrm{C}_{2}$ and $\mathrm{Cr}_{7} \mathrm{C}_{3}$ ) and intermetallic compound (tetragonal $\delta-\mathrm{Cr}_{7} \mathrm{Ni}_{3}$ ). The chromium carbides in $\mathrm{Ni}$ matrix are used with success at temperatures higher than $540{ }^{\circ} \mathrm{C}$ [13] and are sustained for the thermal barrier role from the intermediate layer based on $\mathrm{Al}_{2} \mathrm{O}_{3}$; 
- for the MgZrO - NiCr coating: metallic and intermetallic compound of cubic structure (Cr, $\left.\mathrm{Mg}_{6} \mathrm{Ni}, \mathrm{Ni}, \beta-\mathrm{Zr}\right)$;

- for the $\mathrm{ZrO}-\mathrm{CaO}$ coating: oxides (tetragonal $\mathrm{CaO}_{2}$ and $\mathrm{ZrO}_{2}$ and monoclinic $\mathrm{ZrO}_{2}$ ).

There were observed also some iron-oxide contaminants $\left(\mathrm{Fe}_{2} \mathrm{O}_{3}, \mathrm{Fe}_{3} \mathrm{O}_{4}\right)$ on the samples, caused by handling and storing the samples after dismantling them from the coating devices.

Table 1. Coatings microhardness and modulus of elasticity

\begin{tabular}{|c|c|c|c|c|c|c|c|c|}
\hline $\begin{array}{l}\text { Coating } \\
\text { type }\end{array}$ & E valu & $\begin{array}{l}\text { or } 3 \text { po } \\
\text { (GPa) }\end{array}$ & & $\begin{array}{l}\text { Average E } \\
\text { value (GPa) }\end{array}$ & $\begin{array}{l}\text { Microh } \\
\text { in } 3 \text { poil }\end{array}$ & $\begin{array}{l}\text { dness v } \\
\text { s (GPa }\end{array}$ & & $\begin{array}{l}\text { Average } \\
\text { microhardness } \\
\text { value (GPa) }\end{array}$ \\
\hline 1 & 69,06 & 53,57 & 67,88 & 63,50 & 1,297 & 0,938 & 1,306 & 1,180 \\
\hline 2 & 61,03 & 53,74 & 51,13 & 55,3 & 0,817 & 0,711 & 0,721 & 0,749 \\
\hline 3 & 72,94 & 82,29 & 55,12 & 70,11 & 1,369 & 1,515 & 1,038 & 1,307 \\
\hline
\end{tabular}
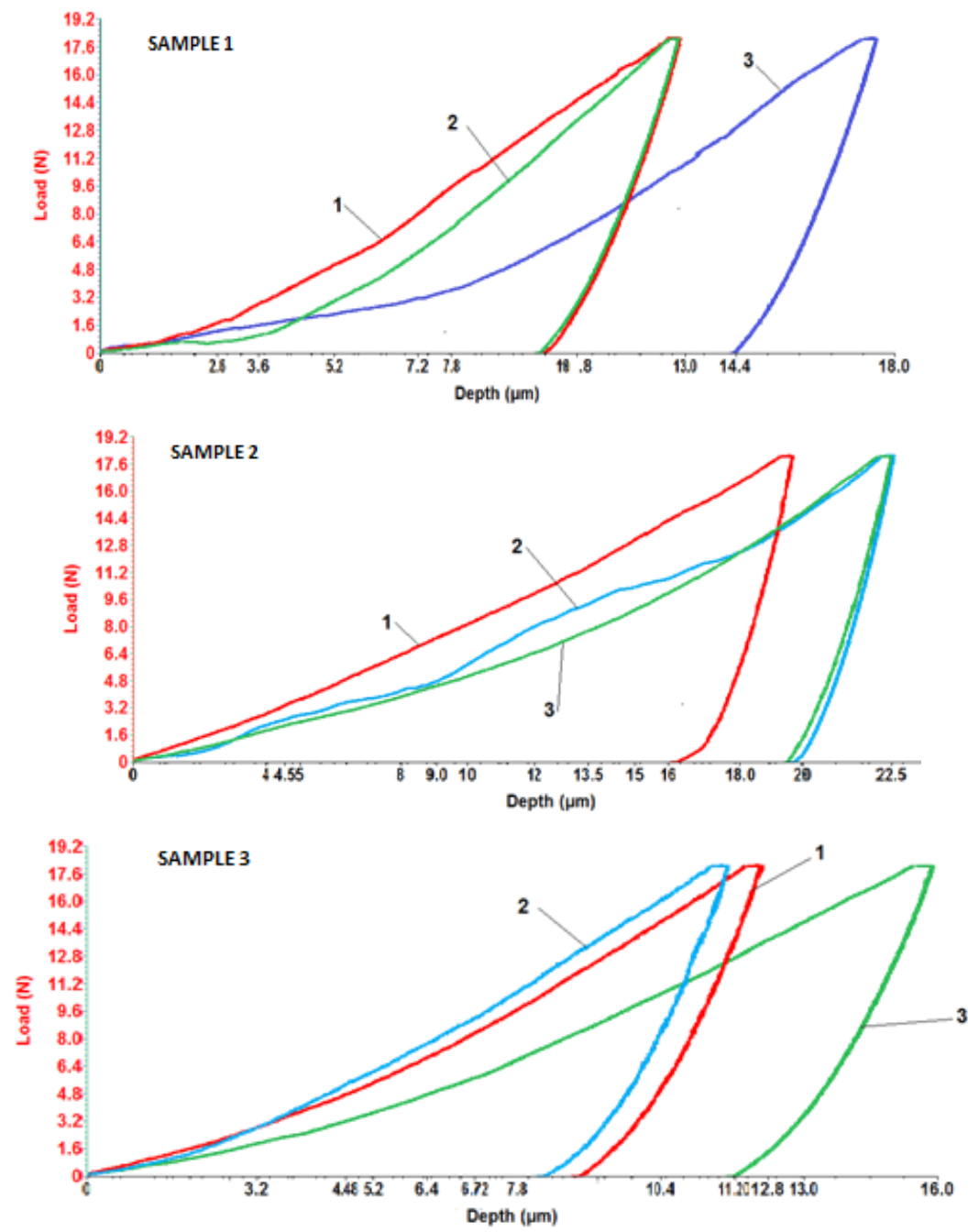

Fig. 5. "Load - depth" indentation curves for three points (1, 2 and 3): a) S1; b) S2; c) S3. 
The microindentation results are presented in table 1 and in Fig. 5. In Table 1 are synthesized the measurements of coatings microhardness and modulus of elasticity resulted from the microindentation tests. Comparatively, the smallest value of the microhardness is observed in case of the sample 2 - the MgZrO - NiCr coating, which can be explained in terms of the lamellar and porous structure specific to the thermal spray coatings.

It is obvious that the "load - depth" indentation curves are not following a similar path, thus we can conclude that the microstructure is not perfectly homogenous and uniform, presenting surface variations.

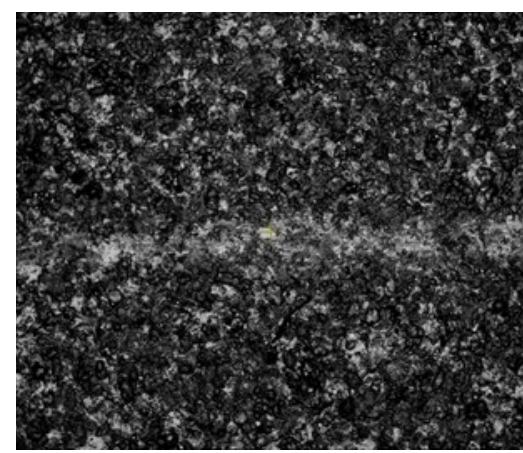

a)

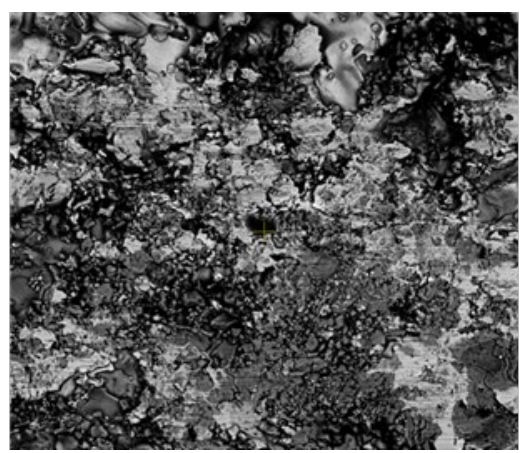

b)

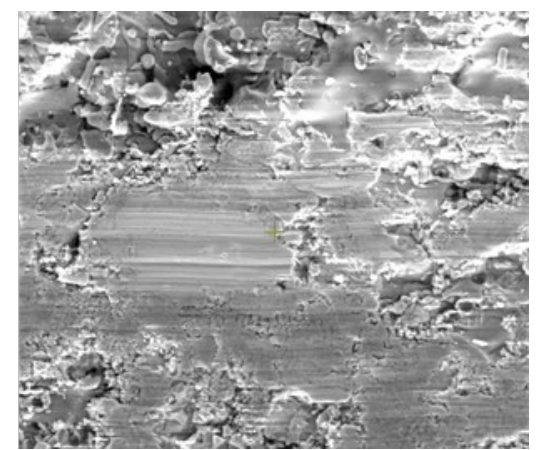

c)

Fig. 6. SEM images of the $\mathrm{Cr}_{2} \mathrm{C}_{3}-\mathrm{NiCr}$ coating at the final (a, 100x) and start point (b, c, 1000x)

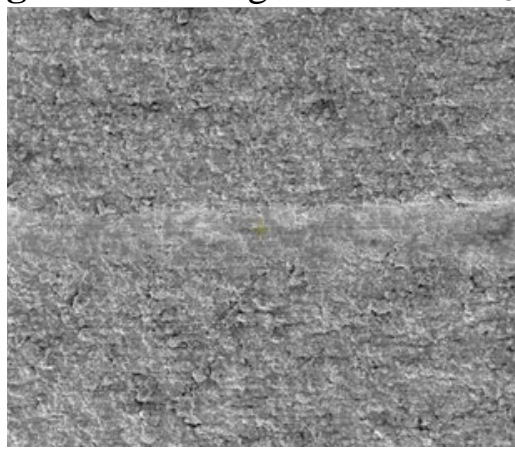

a)

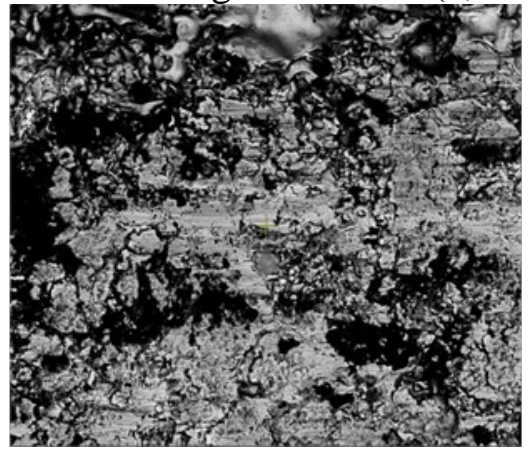

b)

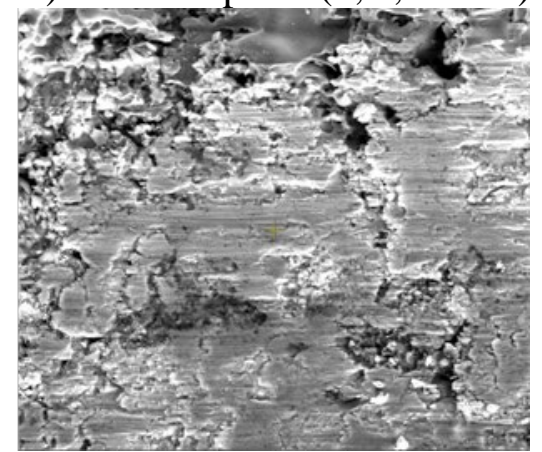

c)

Fig. 7. SEM images of the MgZrO-NiCr coating at the final (a, 100x) and start point (b,c, 1000x)

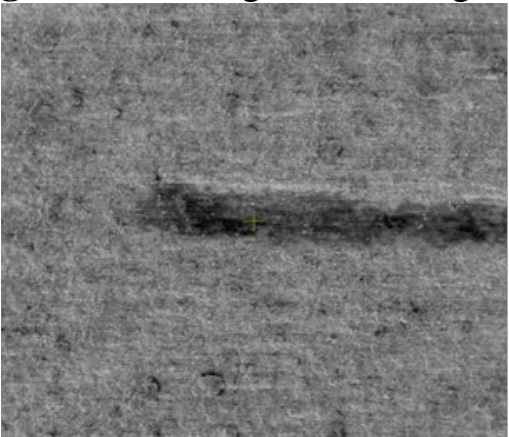

a)

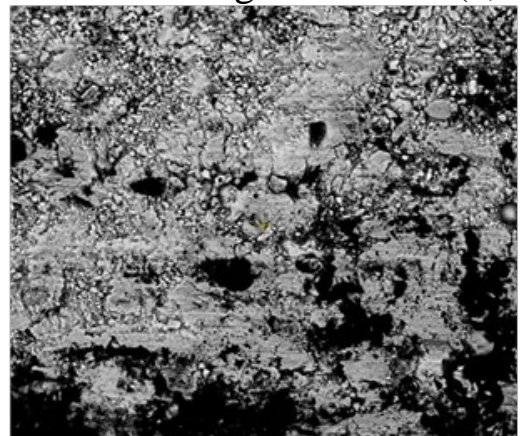

b)

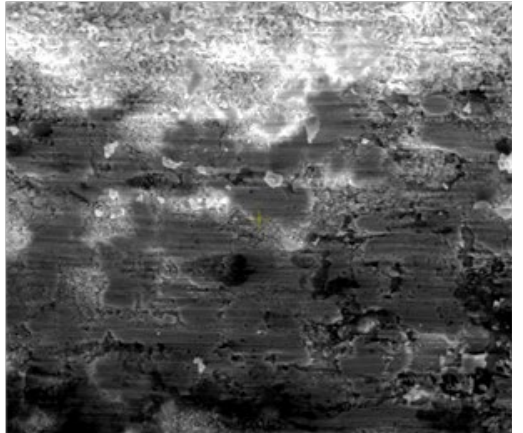

c)

Fig. 8. SEM images of the: $\mathrm{ZrO}-\mathrm{CaO}$ coating at the final (a, 100x) and start point (b, c, 1000x)

Fig. 6, 7, 8 presents the scratch mark aspects resulted after the scratch tests, observed at the beginning and at the end of the scratch marks, for each of the three layers. It is observed that in the 
start points, where the applied force is maximum, the coatings exhibited some plastic deformations in case of samples 1 and 2 and some delaminations in case of sample 3.

\section{Summary}

The structure of these coatings is lamellar, specific to layers made by thermal deposition in the plasma jet, and the component phases in the three cases can provide both the resistance to thermal and mechanical stresses,

On the basis of the SEM images, we can state that in the case of samples 1 and 2 only slight deformation of the layer deposited as thermal barrier occurred; the bonding layer was not exposed. The same cannot be said in case of sample 3, where we observe on both the secondary electron images (a and c) and those made in phase contrast (b and d) that the bonding layer was exposed after the type test scratch. Following those tests it was observed that the coatings are physically suited for further tests as thermal barrier coatings on the valve discs of internal combustion engines.

\section{References}

[1] S.M. Meier, D.K. Gupta, The Evolution of Thermal Barrier Coatings in Gas Turbine Engine Applications, J. Eng. Gas Turbine Power Trans. $116 \quad$ (1994) 250-257. https://doi.org/10.1115/1.2906801

[2] J.R. Nicholls, Advances in coating design for high-performance gas turbines, MRS Bull., 28 (2003) 659-670. https://doi.org/10.1557/mrs2003.194

[3] I. Gurrappa, A. Sambasiva Rao, Thermal barrier coatings for enhanced efficiency of gas turbine engines, Surf. Coat. Technol. $201 \quad$ (2006) 3016-3029. https://doi.org/10.1016/j.surfcoat.2006.06.026

[4] M.J. Pomeroy, Coatings for gas turbine materials and long term stability issues, Mater. Des. 26 (2005) 223-231. https://doi.org/10.1016/j.matdes.2004.02.005

[5] G.W. Goward, Progress in coatings for gas turbine airfoils, Surf. Coat. Technol. 108-109 (1998) 73-79. https://doi.org/10.1016/S0257-8972(98)00667-7

[6] I. Kvernes, E. Lugscheider, Thick Thermal Barrier Coatings for Diesel Engines, Surf. Eng. 11 (1995) 296-300. https://doi.org/10.1179/sur.1995.11.4.296

[7] D.W. Parker, Mater. Des. 13 (1992) 345-351. https://doi.org/10.1016/0261-3069(92)90005-3

[8] M. Ekström, A. Thibblin, A. Tjernberg, C. Blomqvist, S. Jonsson, Evaluation of internal thermal barrier coatings for exhaust manifolds, Surf. Coat. Technol. 272 (2015) 198-212. https://doi.org/10.1016/j.surfcoat.2015.04.005

[9] R.A. Miller, Oxidation-Based Model for Thermal Barrier Coating Life, J. Am. Ceram. Soc. 67 (1984) 517-521. https://doi.org/10.1111/j.1151-2916.1984.tb19162.x

[10] K.A. Khor, Y.W. Gu, Thermal properties of plasma-sprayed functionally graded thermal barrier coatings, Thin Solid Films 372 (2000) 104-113. https://doi.org/10.1016/S00406090(00)01024-5

[11] C. Zhou, N. Wang, Z. Wang, S. Gong, H. Xu, Thermal cycling life and thermal diffusivity of a plasma-sprayed nanostructured thermal barrier coating, Scripta Mater. 51 (2004) 945-948. https://doi.org/10.1016/j.scriptamat.2004.07.024 
[12] U. Schulz, C. Leyens, K. Fritscher, M. Peters, B. Saruhan-Brings, O. Lavigne, J.-M. Dorvaux, M. Poulain, R. Mévrel, M. Caliez, Some recent trends in research and technology of advanced thermal barrier coatings, Aerosp. Sci. Technol. 7 (2003) 73-80. https://doi.org/10.1016/S12709638(02)00003-2

[13] Davis J. R. (ed.) (2004) Handbook of Thermal Spray Technology (pub.) ASM Int. Materials Park OH, USA. 